\title{
ENERGY CONSUMPTION BY THE TYPE OF ENERGY CARRIER USED IN RESIDENTIAL SECTOR IN CITY OF PRISTINA
}

\author{
${ }^{1}$ Petrit AHMETI, ${ }^{2}$ István KISTELEGDI" \\ ${ }^{1}$ Breuer Marcel Doctoral School, Faculty of Engineering and Information Technology \\ University of Pécs, 7624 Pécs, Hungary, Boszorkány út 2 and Faculty of Architecture and \\ Spatial Planning, University for Business and Technology, Kalabria, 10000 Pristina \\ Republic of Kosovo, e-mail: petrit.ahmeti@ubt-uni.net \\ ${ }^{2}$ Energy Design research group, Janos Szentagothai Research Center, University of Pecs \\ Ifjúság útja 20, 7624 Pécs, Hungary, e-mail: kistelegdisoma@mik.pte.hu
}

Received 25 May 2018; accepted 22 October 2018

\begin{abstract}
Residential sector represents the largest energy consumer in the city of Pristina, as a capital of Republic of Kosovo. This is also the most diverse sector in terms of the energy sources used for space heating. Detailed analysis of different heating energy sources is pivotal for understanding the current situation as well as for any future systematic action in this field. In general, the main energy sources used for heating are known but the determination of their share still remains a challenge.

Main focus of the current research is to identify the key heating energy sources, to analyze their share in different zones of Pristina, and to present the heated versus living area per different energy sources within dwellings.

Data gathered in the field and presented in this paper are considered to be a first step in comprehensive analysis of the residential sector energy consumption in Pristina.
\end{abstract}

Keywords: Residential sector, Heating energy, Energy sources, Heating performance

\section{Introduction}

Disproportion of the domestic energy generation and consumption has been one of the main challenges during the last two decades in Kosovo. Lignite Thermal Power Plants Kosovo A and Kosovo B supply 97\% of total electricity generation in Kosovo[1, pp. 11], while the energy need rapidly grows as a result of urban sprawl, especially in Pristina.

\footnotetext{
${ }^{*}$ Corresponding Author
} 
Based on official statistics, from the overall electricity use in Kosovo, the largest share comes from residential sector with 59\%, during 2018 [2, pp. 12-13]. In addition residential sector is also a large contributor on consumption of other energy sources for space heating and cooking from which coal $2.25 \%$, oil products $9.45 \%$, biomass $29.40 \%$, electricity $57.17 \%$, district heating $1.68 \%$ and solar energy $0.05 \%$ [3, pp. 13 ].

Pristina as a capital of Republic of Kosovo represents the largest city in terms of economy, development, population growth as a result of migration, which influenced development of construction industry and especially in residential sector. In terms of scientific research, Pristina may be considered as a representative sample for Kosovo in different fields of study. In this case, in terms of residential sector and heating energy consumption, Pristina represents most of building typologies and heating sources used for heating and could be used as a study sample for entire Kosovo.

The focus of this research is the identification of energy sources used for heating by the residential sector in city of Pristina, types of installed heating systems within dwellings and percentage of heated area within a dwelling, which is also an indicator for living commodity. Absence of sufficient data regarding energy sources used for heating by the residential sector in city of Pristina was the instigation for initiation of this research identifying and understanding key factors of consumption as the underlying drivers of the variations in the residential energy consumption help to predict challenges and opportunities in this area and shed light on the future energy policy [4]. The fundamental concept for the output of the research is data gathering and creation of a data base with structured content regarding heating energy source. The same created data base could be used for further investigations and research activities.

This research shows the results generated based on data gathered in the field through a survey, which covered 1046 dwellings throughout city of Pristina.

\section{Methodology}

Analysis on energy consumption in residential buildings and debates regarding energy efficiency in the housing stock are dominated by physical and technical studies due to the complexity of the energy behaviors problematic and the lack of information on domestic energy usages [5]. Since the energy consumption characteristics of the residential sector are complex, different types of models are investigated by the researchers to assess the performance [6]. Based on the research specificity, topic of which includes mostly data gathering and processing focused on a specific building sector, in this case residential sector, it is generally based on quantitative method by collecting specific data. Beside the data gathering process, the research is focused on result comparative methodology as a supplementary tool to categorize specific data and results. Application of a survey was the most suitable research methodology to reach the desired data. Survey research is used: to answer questions that have been raised, to solve problems that have been observed, to assess needs to establish baselines against which future comparisons can be made [7].

The method of the data gathering has been conducted based on 4 main phases: 
1. Division and fragmentation of urban area of city of Pristina;

2. Calculation of sample size;

3. Questionnaire distribution;

4. Fourth phase included data processing and generation of results.

\subsection{Division and fragmentation of urban area of city of Pristina}

City of Pristina consists of over 20 neighborhoods within the urban boundaries, which contain different building typologies including residential buildings.

Fragmentation of neighborhoods as the first phase of the research facilitated the following phases by structuring the research and survey distribution.

In case of Pristina there are homogenous and heterogeneous residential building zones in terms of building typologies, so the prior focus of this research was to create a map of zones based on residential building typologies after analyzing and identifying the zones within the administrative division zones (neighborhoods). It is important to present an anatomy of energy end-uses in the residential buildings, to assess the energy performance analysis [8], so after the creation of residential building typology zones, it was possible to identify the spreading of different residential building types within the urban zone of Pristina and to create a map of residential building spread based on typology (Fig. 1), [9].

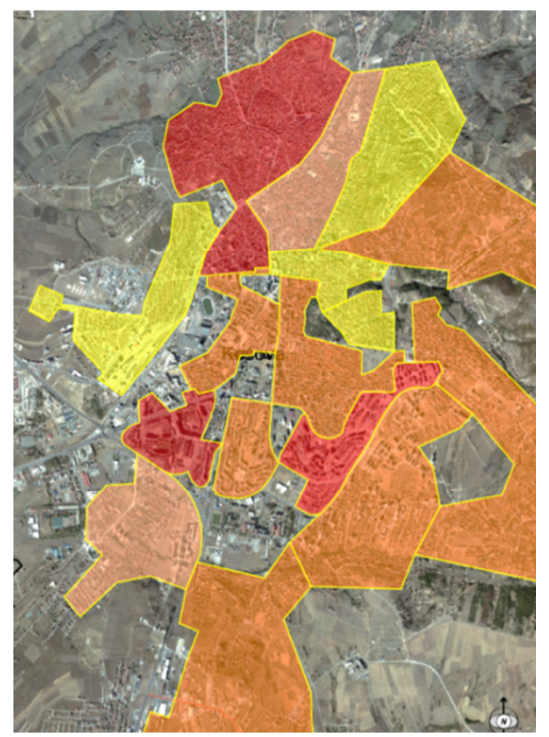

Fig. 1. Fragmentation of neighborhoods in city of Pristina

\subsection{Survey sample size}

Sample size calculation is the preliminary and an indisputable step before starting a survey based research. A sample size is calculated by an equation, which contains all necessary components of the research's subject. 
An investigator often measures several variables and has a number of goals for a survey. Anyone designing a Simple Random Sample (SRS) must decide what amount of sampling error in the estimates is tolerable and must balance the precision of the estimates with the cost of the survey [10, pp. 46]. This particular research is not focused on a single factor or variable to generate conclusive results but takes into consideration several factors, which need to be considered as different variables based on which a specific sample size calculation formula has to be applied. So, in this case the exact sample size estimation formula would be [11, pp. 47]:

$$
n=\frac{\left(z^{2} \cdot p \cdot q\right)+M E^{2}}{M E^{2}+z^{2} \cdot p \cdot q / N}
$$

where $n$ is the sample size; $z$ is the confidence interval (in this case $95 \%$ appropriated, which during calculations is presented as 1.96 standard deviation); $M E$ is the margin of error (in this case $3.0 \%$ is appropriated and during calculations is presented as 0.03 ); $p$ is constant, if you are unsure of the right value to use, set $p$ equal to 0.5 . This will produce a conservative sample size estimate $q=1-p ; N$ is the number of units.

In this case, $N$ is the number of the treated subject, according to Kosovo Agency of Statistics city of Pristina consists of 49463 dwelling units [11].

Applying the confidential interval $95 \%$ and the margin of error $3 \%$, and the first scenario with 49463 dwelling units then:

$$
n=\frac{\left(1.96^{2} \cdot 0.5 \cdot 0.5\right)+0.03^{2}}{0.03^{2}+1.96^{2} \cdot 0.5 \cdot 0.5 / 49463}=1045.55
$$

The value of 1045.55 represents the sample size of the survey based on which the research results will be validated and representative. In this case the sample number is appropriated as 1046, which represents 1046 dwellings as subjects of the research.

\subsection{Survey distribution and data gathering}

Distribution of the questionnaire included a specific analysis and approach to insure a proportional distribution based on number of inhabitants for each neighborhood within city of Pristina. Inhabitant's number and their spread throughout city of Pristina was the groundwork on which the question distribution was based.

According to official data from Municipality of Pristina, city of Pristina has 329300 inhabitants excluding suburbs and villages, spread in 15 administrative zones which contain different types of residential buildings with different population density (Fig. 2).

Distribution of questionnaires based on inhabitants spread throughout city of Pristina insured a nearly exact results and proportional inclusion of each neighborhood with different population density within the research. A proportional generation of results insures a possibility to identify particular data for particular neighborhoods except the general results for the whole city of Pristina (Table I). 


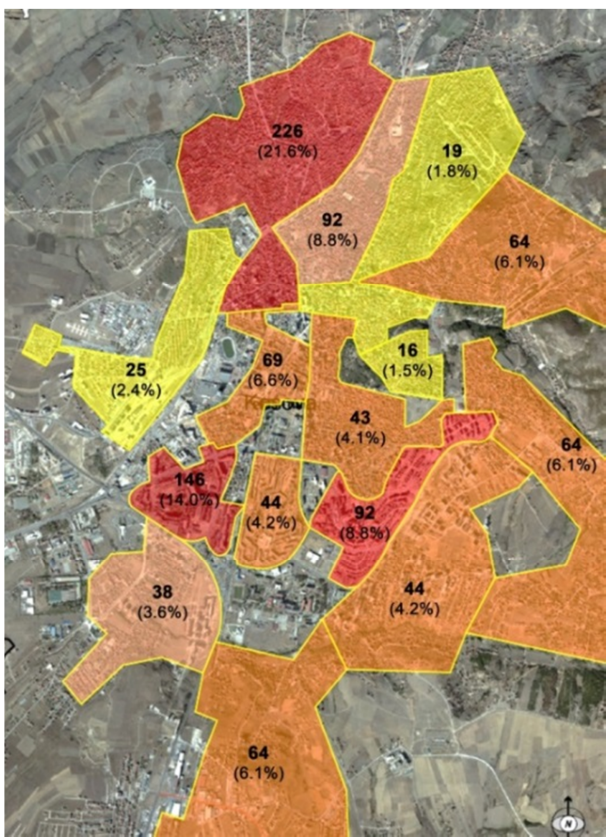

Fig. 2. Map of questionnaire distribution within the city of Pristina

Table I

Distribution of the questionnaires based on inhabitants spread

\begin{tabular}{|r|l|c|c|c|}
\hline $\mathrm{Nr}$ & \multicolumn{1}{|c|}{$\begin{array}{c}\text { Number of } \\
\text { inhabitants } \\
\text { per } \\
\text { neighborhood }\end{array}$} & $\begin{array}{c}\text { Share of each } \\
\text { neighborhood in } \\
\text { total number of } \\
\text { inhabitants }\end{array}$ & $\begin{array}{c}\text { Number of } \\
\text { questionnaires } \\
\text { per } \\
\text { neighborhood }\end{array}$ \\
\hline 1 & 20000 & $6.1 \%$ & 64 \\
2 & Kristina e re & 12000 & $3.6 \%$ & 38 \\
3 & Mati 1 & 14000 & $4.2 \%$ & 44 \\
4 & Matiqan & 20000 & $6.1 \%$ & 64 \\
5 & Dardani/ Lakrishte & 46300 & $14.0 \%$ & 146 \\
6 & Ulpiane & 29000 & $4.2 \%$ & 44 \\
7 & Kodra e Diellit & 5000 & $8.8 \%$ & 92 \\
8 & Velani & 21700 & $1.5 \%$ & 16 \\
9 & Qendra/ Pejton & 8000 & $6.6 \%$ & 69 \\
10 & Arberi/ Prroi i njelmet & 20000 & $2.4 \%$ & 25 \\
11 & Taslixhe/ Sofali/ & 13500 & $6.1 \%$ & 64 \\
12 & Dodona/Muhaxher/Aktash & 71300 & $21 \%$ & 43 \\
13 & Kodra e Trimave/Tophane & 6000 & $1.6 \%$ & 226 \\
14 & Vellushe/ Vreshta & 29000 & $8.8 \%$ & 19 \\
15 & Medrese & 329800 & $100 \%$ & 92 \\
\hline & Total number & & 1046 \\
\hline
\end{tabular}




\subsection{Data processing and generation of results}

The survey process included statistical data gathering for specific components. The processing steps included application of several filtering and formulas based on which it was possible to generate the desired results as main focus of the research. Is was then possible to create a database based on spreadsheet, through which it is possible to analyze specific information regarding specific heating systems or sources for specific building typology within a specific neighborhood, including 1046 dwellings.

\section{Results}

All processed data gathered on field throughout the city of Pristina generated valuable and reliable results. As a result of diverse components and information, processed during the research it was possible to generate various results, which give a clear overview of the current situation of residential sector in terms of heating systems, sources, heating quality and are considered valuable for further detailed research.

The final results present clear data on heating sources used by the residential sector in city of Pristina. As shown in Fig. 3, wood is the main source used for heating by the residential sector with $31.6 \%$ of the overall, followed by district heating $28.1 \%$, electricity $24.5 \%$, coal $7.8 \%$, biomass (pellet) $6.4 \%$, diesel $0.8 \%$, LPG $0.6 \%$ and geothermal $0.3 \%$ (Table II).

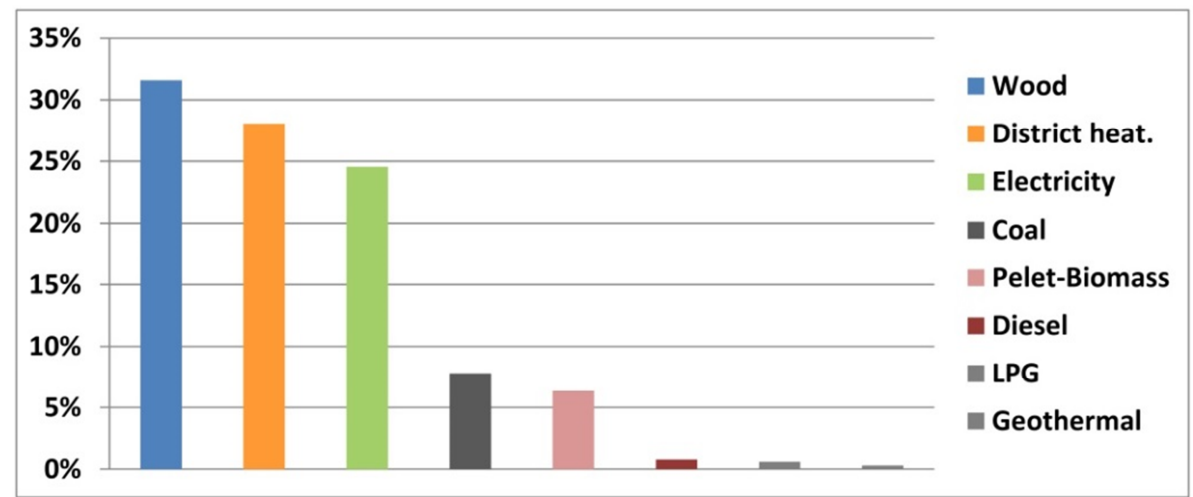

Fig. 3. The share of heating energy sources by residential sector in city of Pristina based on data gathered on field

Table II

The share of heating energy sources by residential sector in city of Pristina based on data gathered on field

\begin{tabular}{|c|c|c|c|c|c|c|c|}
\hline Wood & $\begin{array}{c}\text { District } \\
\text { heating }\end{array}$ & Electricity & Coal & Pellet & Diesel & LPG & Geothermal \\
\hline $31.6 \%$ & $28.1 \%$ & $24.5 \%$ & $7.8 \%$ & $6.4 \%$ & $0.8 \%$ & $0.6 \%$ & $0.3 \%$ \\
\hline
\end{tabular}


Furthermore, the results could be fragmented in a level of each neighborhood, which makes it possible to generate results of diversity heating source usage, Fig. 4-Fig. 11. It is evident that the share of each source for heating differs based on building typology and the period of building construction. Most of single family houses use biomass, wood and coal as a heating source, multifamily and apartment blocks use district heating and electricity as a heating source.

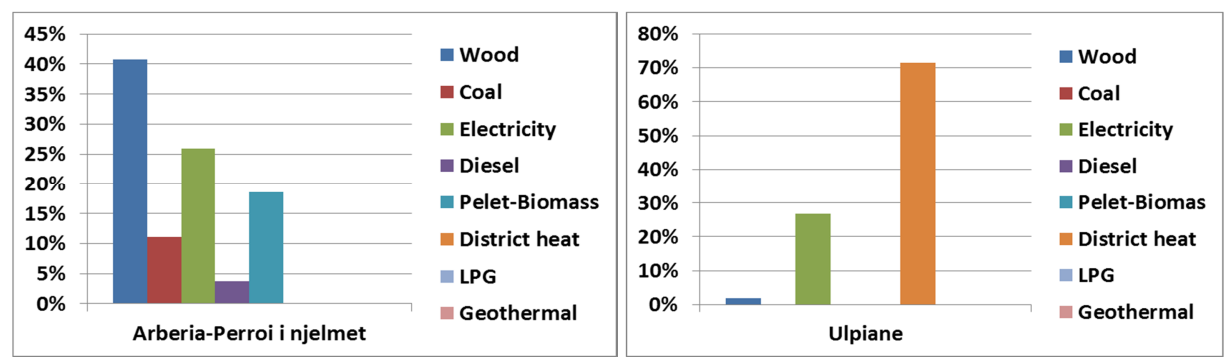

Fig. 4. Heating sources used in Arberia-Perroi i njelmet, Ulpiane

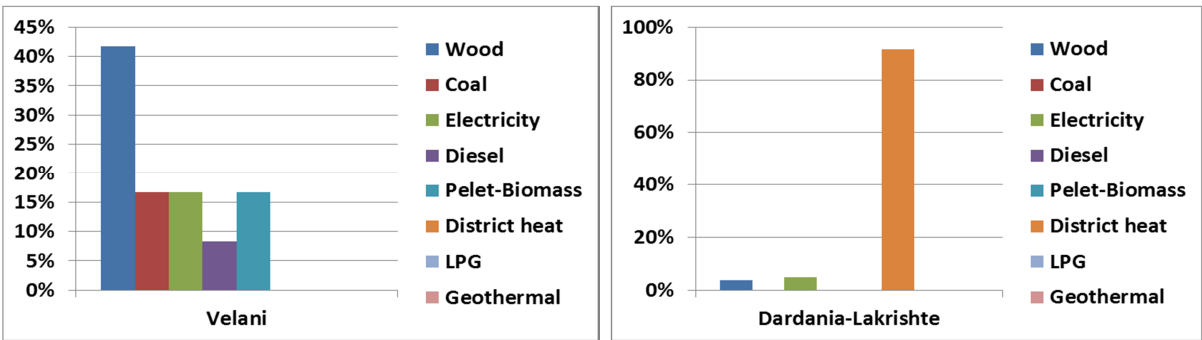

Fig. 5. Heating sources used in Velani, Dardani-Lakrishte



Fig. 6. Heating sources used in Kalabri, Vellushe-Vreshta

The percentage of heated area within a dwelling is another valuable component on setting the living commodity criteria. The percentage of heated within a dwelling is closely connected to the heating sources used by dwellings. The lowest heating percentage of living area are the cases that use LPG (gas) with $66.7 \%$ of dwellings heat less than $25 \%$ of the living area and $33.3 \%$ of dwellings heat between $25-50 \%$ of the living area (Fig. 12). 

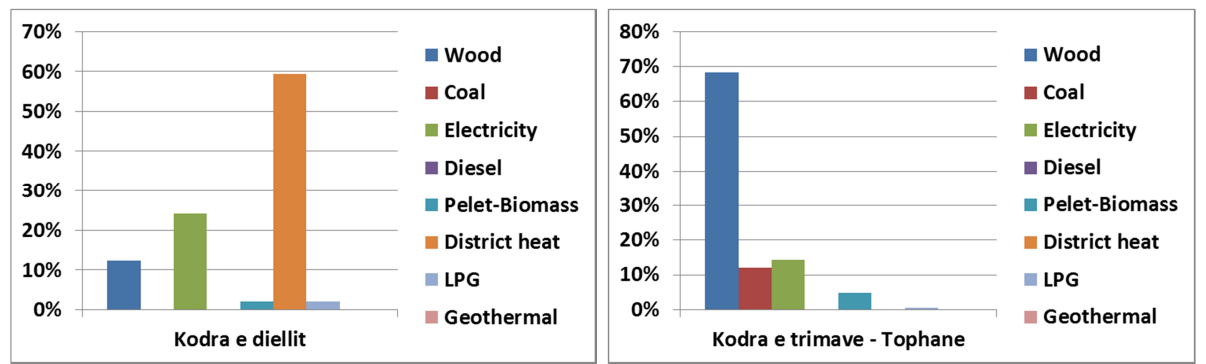

Fig. 7. Heating sources used in Kodra e Diellit, Kodra e trimave-Tophane

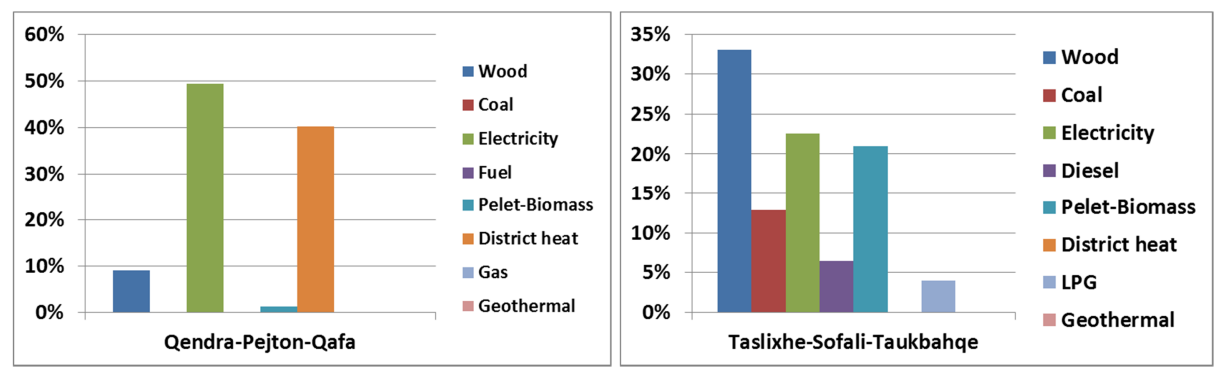

Fig. 8. Heating sources used in Qendra-Pejton-Qafa, Taslixhe-Sofali-Taukbahqe

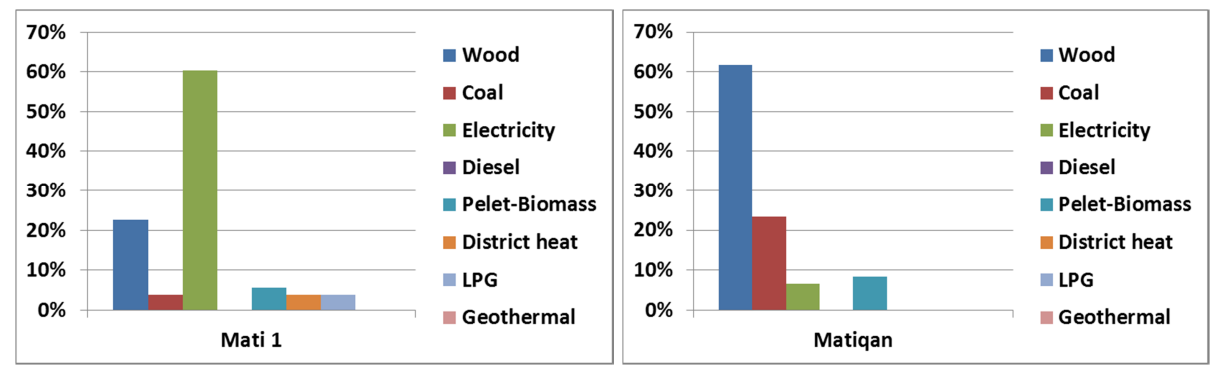

Fig. 9. Heating sources used in Mati 1, Matiqan

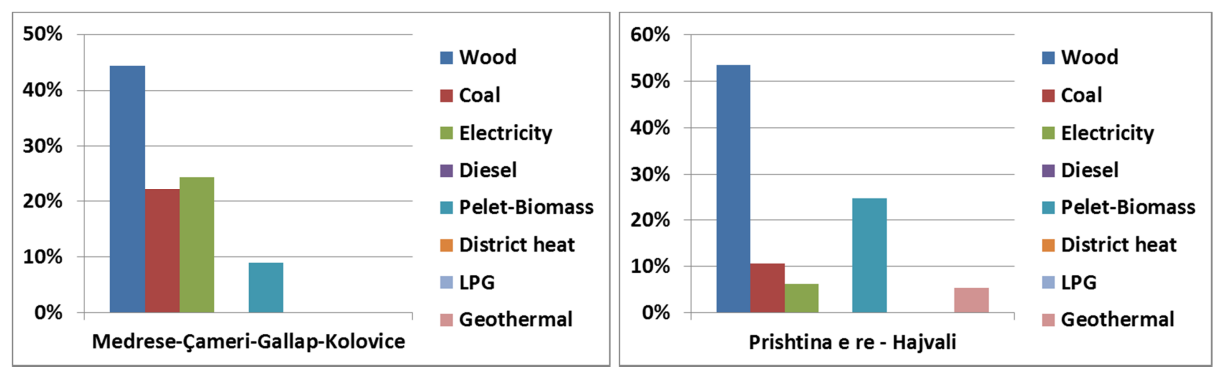

Fig. 10. Heating sources used in Medrese-Çameri-Gallap-Kolovice, Pritshtina Hajvali

Pollack Periodica 14, 2019, 1 
Only $33.7 \%$ of dwelling that use wood as a heating source heat over $75 \%$ of the living area where $35.3 \%$ heat $50-75 \%$ of the living area, $25 \%$ of dwellings heat $25-50 \%$ and $6.1 \%$ heat less than $25 \%$ of the living area. $60.8 \%$ of dwelling that use coal as a heating source heat over $75 \%$ of the living area, $37.8 \%$ of dwellings heat between $50-75 \%$ and only $1.4 \%$ heat between $25-50 \%$ of the overall living area.

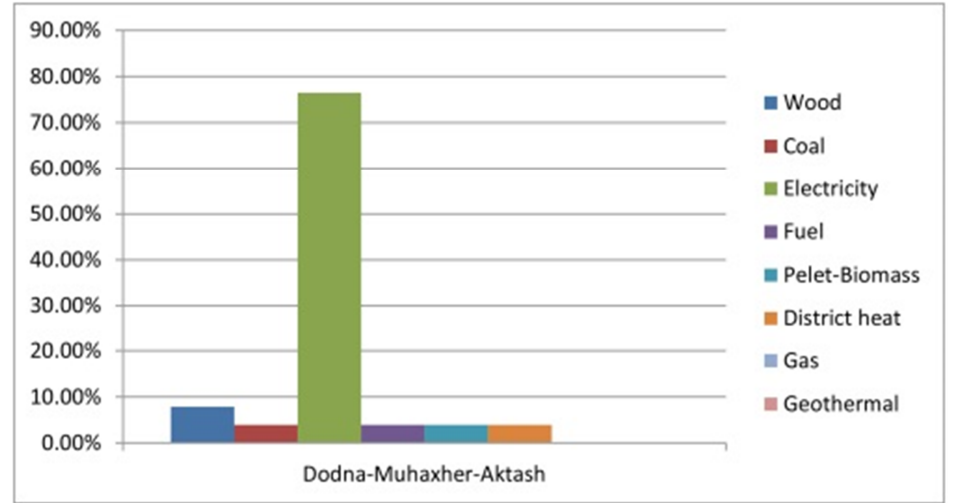

Fig. 11. Heating sources used in Dodona-Muhaxher-Aktash

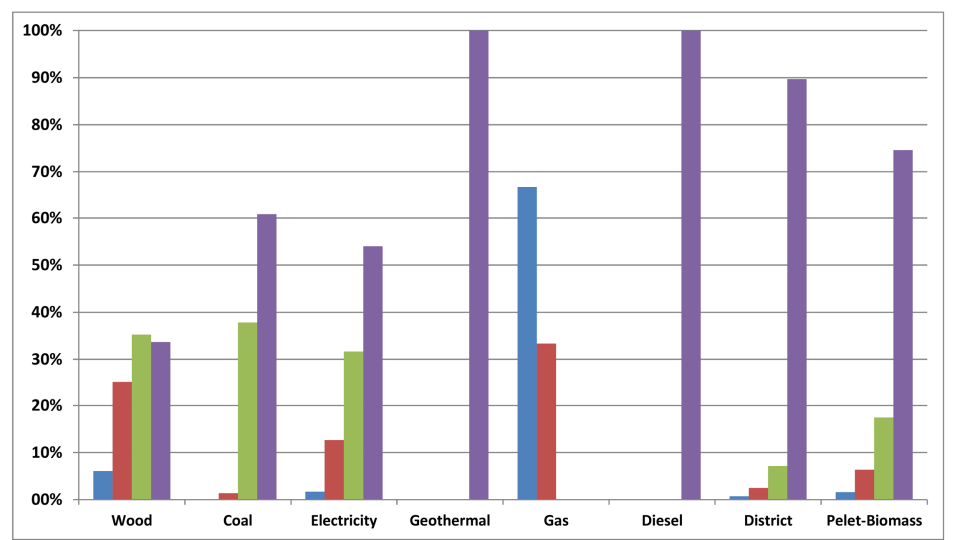

Fig. 12. Percentage of heated area within a dwelling based on heating sources

The percentage of heated within a dwelling is closely connected to the heating sources used by dwellings. The lowest heating percentage of living area are the cases that use LPG (gas) with $66,7 \%$ of dwellings heat less than $25 \%$ of the living area and $33.3 \%$ of dwellings heat between $25-50 \%$ of the living area (Fig. 12). Only $33.7 \%$ of dwelling that use wood as a heating source heat over $75 \%$ of the living area where $35.3 \%$ heat $50-75 \%$ of the living area, $25 \%$ of dwellings heat $25-50 \%$ and $6.1 \%$ heat less than $25 \%$ of the living area. $60.8 \%$ of dwelling that use coal as a heating source heat over $75 \%$ of the living area, $37.8 \%$ of dwellings heat between $50-75 \%$ and only $1.4 \%$ heat between $25-50 \%$ of the overall living area. 
Best cases are usually dwellings that use central heating with geothermal energy and diesel where $100 \%$ of the cases heat over $75 \%$ of the living area. Dwellings connected to the district heating, $89.7 \%$ of the overall treated dwellings heat over $75 \%$ of the living area, $7.1 \%$ heat between $50-75 \%, 2.5 \%$ heat between $25-50 \%$ and only $0.7 \%$ heat less than $25 \%$ of the living area and in most cases this results from technical defects (Table III).

Table III

The share of heating energy sources by residential sector in city of Pristina based on data gathered on field

\begin{tabular}{|c|c|c|c|c|c|c|c|c|}
\hline : & $\begin{array}{l}7 \\
8 \\
3\end{array}$ &  & 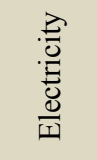 & లే & $\frac{\pi}{0}$ & 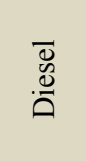 & 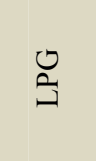 &  \\
\hline $\begin{array}{c}\text { Less than } \\
25 \%\end{array}$ & $6.1 \%$ & $0.0 \%$ & $1.7 \%$ & $0.0 \%$ & $66.7 \%$ & $0.0 \%$ & $0.7 \%$ & $1.6 \%$ \\
\hline $25 \%$ to $50 \%$ & $25 \%$ & $1.4 \%$ & $12.7 \%$ & $0.0 \%$ & $33.3 \%$ & $0.0 \%$ & $2.5 \%$ & $6.3 \%$ \\
\hline $50 \%$ to $75 \%$ & $35.3 \%$ & $37.8 \%$ & $31.6 \%$ & $0.0 \%$ & $0.0 \%$ & $0.0 \%$ & $7.1 \%$ & $17.5 \%$ \\
\hline $\begin{array}{c}\text { More than } \\
75 \%\end{array}$ & $33.7 \%$ & $60.8 \%$ & $54 \%$ & $100 \%$ & $0.0 \%$ & $100 \%$ & $89.7 \%$ & $74.6 \%$ \\
\hline
\end{tabular}

$74.6 \%$ of dwelling that use biomass (pellet) heat over $75 \%$ of the living area, $17.5 \%$ heat between $50-75 \%, 6.3 \%$ heat between $25-50 \%$ and only $1.6 \%$ heat less than $25 \%$ of the living area.

The results show significant ratio of non-environmentally friendly sources used for heating such as coal and electricity, contributing to the higher level of $\mathrm{CO}_{2}$ emissions and resource exploitation.

As a sum of heated area for each heating energy source used by residential sector, it has been possible to calculate the current state of heated are within overall living area treated by the research. Based on the results it is evident that $74 \%$ or more precisely $90168.32 \mathrm{~m}^{2}$ out of $121836.17 \mathrm{~m}^{2}$ of the overall living area treated by the research is heated during the heating season (Fig. 13).

\section{Conclusions}

The results generated based on data gathered on field from 1046 dwelling, showed that the dwellings that use wood, coal and electricity as an energy carrier have a lower living commodity where $66.4 \%, 39.2 \%$ and $45.4 \%$ of these cases, respectively, heat less than $75 \%$ of the living area. This observation can be explained by the fact that individual stoves are used in cases of wood and coal. In the case of electricity this could be a combination of the individual heaters use and a higher price of electricity. Furthermore the percentage of dwellings that use environmentally non-friendly sources such as coal, diesel, and electricity contribute with one third of the overall energy sources used in Pristina, with the tendency of further increase. District heating from 
cogeneration as an efficient and environmentally friendly source of heating still covers $28.1 \%$ of the overall residential sector in city of Pristina.



Fig. 13. Heated area of the total treated living area

\section{Recommendations}

To increase the level of living commodity by heating larger percentage of the living area and at the same time to decrease the level of $\mathrm{CO}_{2}$ emission, an improvement scenario could be based on 3 key points:

1. Building envelope renovation measures;

2. Installation of centralized heating systems instead of individual heaters; and

3. Support the residential sector in legislative and financial means to use 'green systems' with focus on existing cogeneration district heating, implementation of new capacities of biomass district heating, combined with heat pumps and/or solar systems.

Expected results are to decrease energy consumption and use of coal and electricity as a heating source, which would also decrease the level of pollution in city of Pristina. Understanding the factors that drive household's energy consumption, as well as their decision to switch to cleaner energy sources, is vital for shifting public policies and focus toward a more efficient and environmental friendly energy systems [12]. Renewable energy plays a key role in reducing greenhouse gas (for example $\mathrm{CO}_{2}$ ) emissions and other forms of pollution, diversifying and improving the security of energy supply. European Union member states agreed on legally binding national targets for increasing the share of renewable energy in order to achieve a $20 \%$ share for the entire Union by 2020 [13]. 


\section{Acknowledgements}

This research was carried out with support of the University of Pecs, Janos Szentagothai Research Centre, Energy Design Research Group.

\section{Open Access statement}

This is an open-access article distributed under the terms of the Creative Commons Attribution 4.0 International License (https://creativecommons.org/licenses/by/4.0/), which permits unrestricted use, distribution, and reproduction in any medium, provided the original author and source are credited, a link to the CC License is provided, and changes - if any - are indicated. (SID_1)

\section{References}

[1] Ministry of Economic Development, Energy Strategy of the Republic of Kosovo, 20162025, (in Albanian) Pristina, Republic of Kosovo, 2016.

[2] Kosovo Agency of Statistics, Seria 3, Statistikat Ekonomike Bilanci i Energjisë TM1 2018, (in Albanian) 2018, pp. 12-13.

[3] Ministry of Energy and Mining, Kosovo Energy Efficiency Action Plan (Keep) (20102018), (in Albanian) Pristina, Republic of Kosovo, 2011.

[4] Njami A., Shakouri H. G., Keramati A. Energy consumption in the residential sector: a study on critical factors, International Journal of Sustainable Energy, Vol. 35, No. 7, 2016, pp. 645-663.

[5] Belaid F., Garcia T. Understanding the spectrum of residential energy-saving behaviors: French evidence using disaggregated data, Energy Economics, Vol. 57, 2016, pp. 204-214.

[6] Perera D. W. U., Halstensen M., Skeie N. O. Prediction of space heating energy consumption in cabins based on multivariate regression modeling, International Journal of Modeling and Optimization, Vol. 5, No. 6, 2015, pp. 385-392.

[7] Isaac S., Michael, W. B. Handbook in research and evaluation: A collection of principles, methods, and strategies useful in the planning, design, and evaluation of studies in education and the behavioral sciences, (3rd Ed.), San Diego, Educational and Industrial Testing Services, 1997.

[8] Radha C. H., Kistelegdi I. Thermal performance analysis of Sabunkaran residential building typology, Pollack Periodica, Vol. 12, No. 2, 2017, pp. 151-162.

[9] Ahmeti P., Dalipi I., Basha A., Kistelegdi I. Current heating energy demand by the residential sector in City Pristina based on the main resources, Pollack Periodica, Vol. 12, No. 1, 2017, pp. 147-158.

[10] Lohr S. L. Sampling design and analysis, Second Edition, 1999.

[11] Kosovo Agency of Statistics, Dwellings and buildings by municipalities, 2013.

[12] Damette O., Delacote P., Del Lo. G., Households energy consumption and transition toward cleaner energy sources, Energy Policy, Vol. 113, 2018, pp. 751-64.

[13] Talamon A. Global renewable energy trends and Hungary, International Review of Applied Sciences and Engineering, Vol. 3, No. 1, 2012, pp. 81-85. 